\title{
Erratum to: "Impact of Season and Road on Stream Crossings and River Water Quality in Darabkola, Hyrcanian Forest ${ }^{1,}$ [Water Resources 43, 369 (2016)]
}

Mananeh Akbarimehr ${ }^{a}$ * , Seyed Ataollah Hosseini ${ }^{b}$, Fatemeh Shariatic ${ }^{c}$, and Seyed Mohammad Hodjati ${ }^{d}$

${ }^{a}$ Department of Forestry, Sari Agricultural Sciences and Natural Resources University, Mazandaran, Iran

${ }^{b}$ Department of Forestry and Forest Economic, University of Tehran, Tehran, Iran

${ }^{c}$ Department of Environment, Lahijan Branch, Islamic Azad University, Lahijan, Iran

${ }^{d}$ Department of Forestry, Sari Agricultural Sciences and Natural Resources University, Mazandaran, Iran

*e_mail: Akbarimehr.mananeh@yahoo.com

Submitted September 15, 2016; accepted for publication September 15, 2016

DOI: $10.1134 / \mathrm{S} 0097807817010110$

The affiliation under the symbol " $c$ " should read:

Department of Environment, Lahijan Branch, Islamic Azad University, Lahijan, Iran.

\footnotetext{
1 The article is published in the original.
} 